\title{
Leaching performance of low grade zinc oxide ore in the system of $\mathrm{NH}_{3}$ -
}

\section{$\left(\mathrm{NH}_{4}\right)_{2} \mathrm{SO}_{4}-\mathrm{H}_{2} \mathrm{O}$}

\author{
Kaiwei Song ${ }^{1,2, a}$,Jingjie Yuan ${ }^{1,2, b}$, Peilun Shen ${ }^{1,2, \mathrm{c}}$, Shoukai Yan ${ }^{1,2, \mathrm{~d}}$, Fei \\ $\mathrm{Li}^{1,2, \mathrm{e}}$, Dianwen $\operatorname{liu}^{1,2, \mathrm{f}^{*}}$ \\ ${ }^{1}$ Faculty of Land Resource Engineering, Kunming University of Science and Technology, Kunming \\ 650093, Yunnan, China \\ ${ }^{2}$ State Key Laboratory of Complex Nonferrous Metal Resource Cleaning Utilization, Kunming, \\ Yunnan 650093, China \\ asongkaiwei@126.com, b370131803@qq.com, ${ }^{\mathrm{c}} 546217044 @ q q . c o m,{ }^{\mathrm{d}} 874992622 @ q q . c o m$, \\ e274583415@qq.com, ${ }^{\mathrm{f}^{*}}$ Idwkust@126.com (Corresponding Author)
}

Key words: zinc oxide ore; $\mathrm{NH}_{3}-\left(\mathrm{NH}_{4}\right)_{2} \mathrm{SO}_{4}-\mathrm{H}_{2} \mathrm{O}$ system; ammonia leaching; leaching efficiency ABSTRACT: Leaching test on the oxidized zinc ore from Kashi, Xinjiang Autonomous Region is studied in the $\left(\mathrm{NH}_{4}\right)_{2} \mathrm{SO}_{4}-\mathrm{NH}_{3}-\mathrm{H}_{2} \mathrm{O}$ system; Systematic studies are made to show the effects of various factors on the leaching rate of zinc. The optimum conditions for leaching is finally confirmed, i.e., the grinding fineness is $80 \%-74 \mathrm{um}$, concentration of ammonium sulfate is $2 \mathrm{~mol} / \mathrm{L}$, concentration of ammonia is $4 \mathrm{~mol} / \mathrm{L}$, reaction temperature is $40^{\circ} \mathrm{C}$, the ratio of liquid to solid is $4: 1$; stirring rate is $300 \mathrm{rpm}$ and leaching time is $3 \mathrm{~h}$. Ultimately, the leaching rate of $\mathrm{Zn}$ could reach more than $91 \%$.

\section{Introduction}

As one of the two primary of oxide zinc processing, flotation technology receive the reputation of the central and full-blown method ${ }^{[1]}$. However it is difficult to select zinc from complicate and low grade zinc oxide ore by flotation and the cost is high. Therefore, leaching becomes the best technology for zinc oxide ore, which is approved by a lot of researchers made both at home and abroad. Particularly, the ammonia leaching and its joint technology is the main development direction concerning the low grade zinc oxide ore ${ }^{[2,3,4,5]}$.

The zinc oxide ore from Kashi, Xinjiang Autonomous Region is a typical low grade one with alkaline gangues and high content of silicon and slime. Ammonia leaching is likely to be the best technology for the treatment of zinc. This passage systematically analyzes the main factors and their influence on leaching efficiency of zinc oxide ore.

\section{Experiment}

\section{Materials and Apparatus}

The ore used in the experiment from Kashi, Xinjiang Autonomous Region of China. After being ground and dry sieved, the ore was analyzed in Kunming Metallurgical Research Institute. Table 1 shows The chemical analysis of the raw ore, and Table 2 shows the mineralogical composition of zinc in the ore, respectively. The tables show that the raw ore contains smithsonite 
$\left(\mathrm{ZnCO}_{3}\right)$, willemite $\left(\mathrm{ZnSiO}_{4}\right)$ as major minerals, as well as magnesium oxide $(\mathrm{MgO})$,calcium oxide $(\mathrm{CaO})$, and quartz $\left(\mathrm{SiO}_{2}\right)$ as gangue minerals.

Table 1 Chemical analysis of raw ore (\%wt.)

\begin{tabular}{ccccc}
\hline Element & $\mathrm{Zn}$ & $\mathrm{Pb}$ & $\mathrm{TFe}$ & $\mathrm{S}$ \\
\hline Content $(\%)$ & 1.81 & 0.26 & 1.49 & 0.37 \\
\hline element & $\mathrm{Al}_{2} \mathrm{O}_{3}$ & $\mathrm{MgO}$ & $\mathrm{CaO}$ & $\mathrm{SiO}_{2}$ \\
\hline Content $(\%)$ & 2.24 & 8.36 & 16.49 & 43.79 \\
\hline
\end{tabular}

Table 2 Mineralogical composition of zinc in the ore (\%wt.)

\begin{tabular}{cccccc}
\hline Substance & $\mathrm{ZnCO}_{3}$ & $\mathrm{ZnSiO}_{4}$ & $\mathrm{ZnS}$ & $\begin{array}{c}\mathrm{ZnFe}_{2} \mathrm{O}_{4} \text { and } \\
\text { Others }\end{array}$ & $\begin{array}{c}\text { Total } \\
\text { zinc }\end{array}$ \\
\hline content/\% & 1.09 & 0.12 & 0.05 & 0.55 & 1.81 \\
Distribution/\% & 60.22 & 6.63 & 2.78 & 30.37 & 100.00 \\
\hline
\end{tabular}

Reagent grade chemicals were used for all the experiments. The leaching agents used were ammonia and ammonium sulfate which were provided by Tianjin Chemical Reagents Company, and the distilled water was used throughout the leaching process. The grinding using ball mill (XMQ-67 Wuhan Resource Exploration Mechanical Factory, China), Precision force electric Blender (DSX-120 Hangzhou instrument electric machine Ltd., China) was used for agitated leaching.

\section{Experimental Methods}

Firstly, the zinc oxide ore that has been crushed will be ground into different fineness by ball mill according to the requirement of particle size. Then, weighing a 100g's sample and moving it into three-hole flask which is filled with leaching solution then proceeding agitation leaching in pressure-tight and temperature-constant three-holes flask with backflow condenser placed in one of the holes, in order to reduce the volatility of ammonia and water loss. After that, separating the liquid-solid slurry with suction filter after leaching is completed and washing filter residue three times with distilled water. Finally, the filter residue will be dried in an oven at room temperature in order to forbid the sulfide ore being oxidized into the oxide ore, made samples and sent to the analytical center for further analysis.

\section{Evaluation Method}

Leaching efficiency $(\mathrm{X})$ was calculated according to the Eq. (1):

$$
X=\frac{M a-n \beta}{M a} \times 100 \%
$$

Where $\mathrm{M}=$ the weight of sample before leaching $(\mathrm{g}), \mathrm{m}=$ the weight of leaching residue $(\mathrm{g})$, $\mathrm{a}=$ the zinc grade of raw ore $(\%), \beta=$ the zinc grade of leaching residue $(\%)$.

\section{Results and Discussion}

\section{Single-factor conditional experiments Effect of grinding fineness}

To determine the effect of particle size on leaching efficiency of zinc, leaching conditions were as follows: total ammonia concentration as $8 \mathrm{~mol} / \mathrm{l}$; ammonia-to-total ammonia molar ratio of $1 / 2$; reaction temperature at $25^{\circ} \mathrm{C}$; a liquid-to-solid ratio of 4 ; leaching time $3 \mathrm{~h}$; with a stirring rate of 300rpm. The results are shown in Fig.1. And Fig.1 shows that leaching efficiency will increase as 
the grinding fineness increases. And at $80 \%-74 \mathrm{um}$, the zinc extraction reaches $91.19 \%$. After that, increase the fineness continuously, the addition of leaching efficiency is unconspicuous. That's because when the particle size of the ore is too thin, there will produce the aggregation among leaching slurry and reducing the dispersion of particles. Consequently, there is no obvious addition of zinc extraction and even will go against leaching as the fineness increases continuously. Therefore, at the following tests, selecting the sample with the grinding fineness $80 \%-74 \mathrm{um}$.

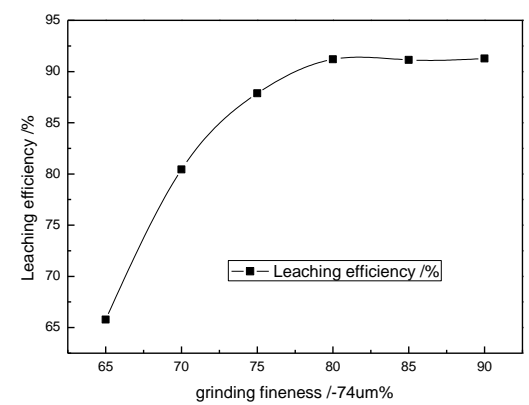

Fig.1 Effect of grinding fineness on leaching efficiency of zinc

\section{Effect of total ammonia concentration}

To investigate the effect of total ammonia concentration on leaching efficiency of zinc, the leaching conditions were as follows: ammonia-to-total ammonia molar ratio of $1 / 2$; reaction temperature at $25^{\circ} \mathrm{C}$; a liquid-to-solid ratio of 4; leaching time $3 \mathrm{~h}$; with a stirring rate of 300rpm. The results are shown in Fig. 2. It is easily observed that the leaching efficiency of zinc rises up as the concentration of total ammonia increases. And when the total ammonia concentration is in the range of $1-8 \mathrm{~mol} / \mathrm{L}$, the zinc extraction rate increases quickly. However, in the range of $8-9 \mathrm{~mol} / \mathrm{L}$ the total ammonia concentration will not have a further improving effect on the zinc extraction, and the leaching rate tends to be changeless. So selecting the total ammonia concentration as $8 \mathrm{~mol} / \mathrm{L}$ to carry out the following experiments.

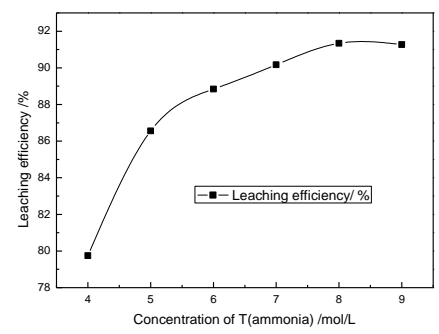

Fig. 2 Effect of total ammonia concentration on leaching efficiency of zinc

\section{Effect of molar ratio of ammonia/total ammonia}

To determine the effect of molar ratio of ammonia/total ammonia on leaching efficiency of zinc, leaching conditions were as follows: total ammonia concentration set as $8 \mathrm{~mol} / \mathrm{L}$, using various molar ratios (from $0 / 8$ to $8 / 8$ ); reaction temperature at $25^{\circ} \mathrm{C}$; a liquid-to-solid ratio of 4 ; leaching time $3 \mathrm{~h}$; with a stirring rate of 300rpm. The results are shown in Fig.3. The curve in the Fig.3 shows the zinc extraction rises up as the molar ratio increases among the range of $0 / 8-4 / 8$. And in the range of $4 / 8-8 / 8$, the leaching efficiency decreases. The data indicates that in the leaching system, using mono ammonia or mono ammonium sulfate as lixiviant will not have the promotion effect on the zinc extraction. And at the ratio of $4 / 8$, the leaching efficiency reaches $91.89 \%$. Therefore, the best molar ratio of ammonia/total ammonia for zinc extraction is $4 / 8$. 


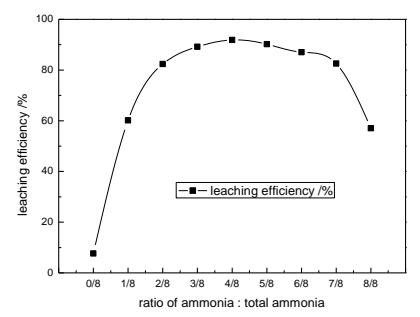

Fig.3 Effect of molar ratio of ammonia/total ammonia on leaching efficiency of zinc

\section{Effect of liquid/solid ratio}

To confirm the effect of liquid/solid ratio on the zinc extraction using various liquid/solid ratios. The leaching conditions employed were as follows: total ammonia concentration 8mol/L; ammonia-to-total ammonia ratio of $1 / 2$; reaction temperature at $25^{\circ} \mathrm{C}$; leaching time $3 \mathrm{~h}$; a stirring rate of 300rpm. The results are shown in Fig.4. As can be seen form Fig.4, zinc extraction increases with the increasing of liquid/solid ratio in the range of 2-4. That is because the viscosity of pulp is reducing as the ratio of liquid/solid increases. After the liquid-solid ratio reaches the proportion of 4 , the leaching efficiency adds more slowly. But the consumption of reagent increases along with liquid-solid ratio. Considering the leaching rate and cost, setting the ratio of liquid/solid as 4.

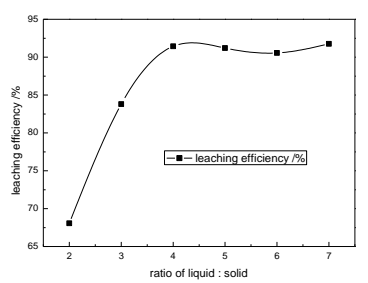

Fig.4 Effect of liquid-solid ratio on leaching efficiency of zinc

\section{Effect of leaching time}

To investigate the effect of leaching time on leaching efficiency of zinc, using various leaching time. The leaching conditions applied were as follows: total ammonia concentration $8 \mathrm{~mol} / \mathrm{L}$; ammonia/total ammonia ratio of $1 / 2$; reaction temperature at $25{ }^{\circ} \mathrm{C}$; a ratio of liquid/solid of 4 ; stirring rate of 300rpm. The results are shown in Fig.5. It shows the leaching efficiency increases with the passage of time from $2 \mathrm{~h}$ to $3 \mathrm{~h}$. When the leaching time is more than $3 \mathrm{~h}$, the leaching rate fluctuates. That is due to hardly keeping the total ammonia concentration constant with extending leaching time. Therefore, selecting 3hours as the optimum leaching time .

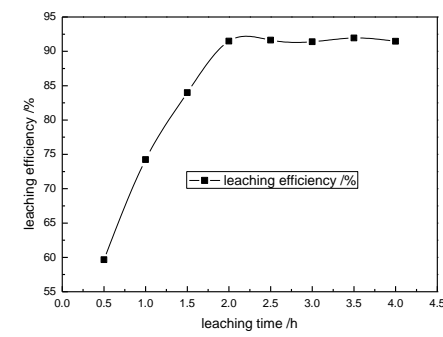

Fig.5 Effect of leaching time on leaching efficiency of zinc

\section{Effect of reaction temperature}

To research the effect of reaction temperature on zinc extraction, varying the temperature. The leaching conditions adopted were as follows: total ammonia concentration 8mol/L; ammonia/total ammonia ratio of $1 / 2$; liquid/solid ratio of 4 ; stirring rate of $300 \mathrm{rpm}$; leaching time $3 \mathrm{~h}$. The results 
are shown in Fig.6. It is clear that reaction temperature has apparent effect on zinc extraction. At $40^{\circ} \mathrm{C}$, the leaching efficiency reaches the highest,91.60\%. That is because with the reaction of temperature rising, the spread of lixiviant molecules in leaching solution speeds up, more easily attacks the mineral grains and the stockpile energy of mineral particles increases, so the ability of damage or weakening of the chemical bonds of mineral enhances, and the number of molecules whose kinetic energy is equal to or greater than activation energy increases. While the reaction temperature increases more than $40^{\circ} \mathrm{C}$, the zinc extraction decreases a little. That is because the volatility of ammonia will increase, once the temperature exceeds some point.

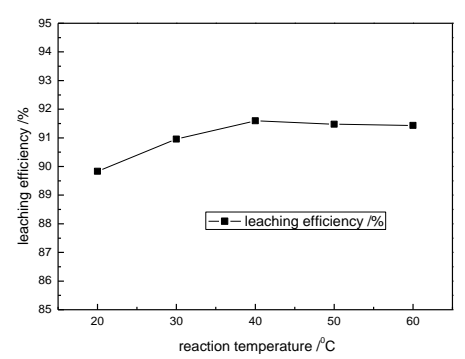

Fig.6 Effect of reaction temperature on leaching efficiency of zinc

\section{Effect of stirring rate}

To examine the effect of stirring rate on zinc extraction, changing the stirring rate. Leaching conditions were as follows: total ammonia concentration $8 \mathrm{~mol} / \mathrm{L}$; ammonia/total ammonia ratio of $1 / 2$;reaction temperature at $40^{\circ} \mathrm{C}$; liquid/ solid ratio of 4 ; leaching time $3 \mathrm{~h}$. The results are shown in Fig.7. The results show that zinc extraction rate increases as the stirring rate rises. Especially, when the stirring rate is in the range of 0-300rpm, it has a significant influence on leaching efficiency. When the stirring speed exceeds 300rpm, the zinc extraction rate tends to be stable. That is because increasing the stirring rate also will increase the relative motion between mineral particles and leaching solution which will impede the leaching process.

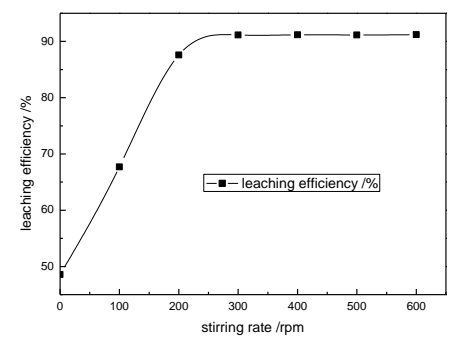

Fig.7 Effect of stirring rate on leaching efficiency of zinc

\section{Verification test}

After systematically examining the influence of various factors on the leaching efficiency of zinc, the optimal technical conditions have been confirmed, viz, the particle size of $80-0.074 \mathrm{~mm}$; concentration of ammonium sulfate $2 \mathrm{~mol} / \mathrm{L}$, concentration of ammonia $4 \mathrm{~mol} / \mathrm{L}$; reaction temperature at $40^{\circ} \mathrm{C}$; a liquid/solid ratio of 4 ; leaching time $3 \mathrm{~h}$; and with a stirring rate of 300rpm. The results of three tests under the upper conditions are shown in Table 3. It is clear that the optimum leaching conditions of the test have proved the correctness of the result because the leaching efficiency of zinc is more than $91 \%$ in the three times of verification experiment. The result is approving. 
Table 3 Results of the Optimum leaching conditions test

\begin{tabular}{ccc}
\hline Test number & $\begin{array}{c}\text { Leaching efficiency of total } \\
\text { zinc }(\%)\end{array}$ & $\begin{array}{c}\text { Leaching efficiency of } \\
\text { leachable zinc }(\%)\end{array}$ \\
\hline AJ-1 & 33.92 & 91.63 \\
AJ-2 & 34.08 & 92.06 \\
AJ-3 & 33.91 & 91.59 \\
Average & 33.97 & 91.76 \\
\hline
\end{tabular}

\section{Conclusions}

On the basis of the discussion above, some conclusions can be drawn as follows :

(1) The studies of technological mineralogy indicate that the zinc oxide ore has the characters of high content of calcium, magnesium and silicon. It belongs to mixed sulfide-oxide zinc ore with alkaline gangue-minerals.

(2) The optimum conditions are identified as follow: the grinding fineness is $80 \%$ $-0.074 \mathrm{~mm}$, concentration of ammonium sulfate is $2 \mathrm{~mol} / \mathrm{l}$, concentration of ammonia is 4 $\mathrm{mol} / \mathrm{l}$, reaction temperature is $40^{\circ} \mathrm{C}$, the ratio of liquid to solid is $4: 1$; stirring rate is $300 \mathrm{rpm}$ and leaching time is $3 \mathrm{~h}$.

(3) The leaching test results show that the leaching process technology is feasible to deal with the zinc oxide ore, and the leaching rate is up to $91.76 \%$.

\section{Acknowledgements}

The financial support for this work from the Science and Technology Planning Project (Grant no.20120033) and the Talents Scientific Research Project (Grant no.14118113) is gratefully appreciated.

\section{Reference}

[1] Moradi, S. and A. J. Monhemius (2011). Mixed sulphide-oxide lead and zinc ores: Problems and solutions. Minerals Engineering 24(10):1062-1076.

[2] Turan, M. D. and M. S. Safarzadeh (2012). Separation of zinc, cadmium and nickel from $\mathrm{ZnO}-\mathrm{CdO}-\mathrm{NiO}$ mixture through baking with ammonium chloride and leaching. Hydrometallurgy 119-120: 1-7.

[3] Ding, Z., et al. (2010). Dissolution kinetics of zinc silicate (hemimorphite) in ammoniacal solution. Hydrometallurgy 104(2): 201-206.

[4] Abkhoshk, E., et al. (2014). "Review of the hydrometallurgical processing of non-sulfide zinc ores." Hydrometallurgy 149: 153-167.

[5] Gargul, K. and B. Boryczko (2015). Removal of zinc from dusts and sludges from basic oxygen furnaces in the process of ammoniacal leaching. Archives of Civil and Mechanical Engineering 15(1): 179-187. 